\title{
Laser powder-bed fusion of Inconel 718 to manufacture turbine blades
}

\author{
Fabrizia Caiazzo $^{1} \cdot$ Vittorio Alfieri $^{1} \cdot$ Gaetano Corrado $^{1}$ • Paolo Argenio ${ }^{1}$
}

Received: 8 May 2017 / Accepted: 18 July 2017 / Published online: 1 August 2017

(C) The Author(s) 2017. This article is an open access publication

\begin{abstract}
In the frame of additive manufacturing of metals, laser powder-bed fusion is investigated in this paper as an advanced industrial prototyping tool to manufacture Inconel 718 turbine blades at a predesign stage before flow production. Expediting of the evaluation of any upgrade to the part is aimed. To this purpose, possible anisotropy of manufacturing is preliminarily investigated via tensile testing at room and elevated temperature as a function of the sloping angle with the building plate; the normalized strength is given and compared with similar studies in the literature. Positioning and proper supporting in manufacturing are discussed; the parts are further investigated to assess their compliance with the intended nominal geometry.
\end{abstract}

Keywords Additive manufacturing - Selective laser melting · Inconel $\cdot$ Anisotropy

Fabrizia Caiazzo

f.caiazzo@unisa.it

Vittorio Alfieri

valfieri@unisa.it

Gaetano Corrado

gcorrado@unisa.it

Paolo Argenio

pargenio@unisa.it

1 Department of Industrial Engineering, University of Salerno, Via Giovanni Paolo II 132, 84084 Fisciano, Italy

\section{Introduction}

New possibilities in lightweight design and direct fabrication of functional end-use parts are offered by additive manufacturing (AM) [1] where the base material is provided layer-bylayer, unlike conventional turning and milling relying on removal from the bulk. Namely, laser powder-bed fusion (LPBF) is a solid freeform fabrication technique based on laser irradiation of metal powder [2]; in this frame, selective laser sintering (SLS) and melting (SLM) are even referred to $[3,4]$. Assemblies are turned into single parts; hence, streamlining of manufacturing and potential elimination of tooling are benefited [5]; moreover, customization is allowed and the mechanical strength of the bulk is achieved upon proper setup. Nevertheless, the resulting surface quality may limit the application if compared with conventional metal manufacturing. Therefore, post-processing treating is required to the purpose of surface modification $[6,7]$.

Among a wide range of possible applications of AM, interest is currently devoted to superalloys for aerospace, automotive, and chemical industry [8], where outstanding combination of mechanical properties and wear resistance is required. In this frame, Inconel 718 (IN718), a solid-solution or precipitation strengthened Ni-based austenite superalloy [9], is receiving increasing interest, as being widely used to produce exhaust pipes, parts for rocket motors, gas turbines, and nuclear reactors.

Two main reasons are driving both scientific and industrial investigation about IN718 AM-made parts. At first, challenges are faced when addressing fabrication of IN718 parts at room temperature with conventional machining due to high shear strength and low material removal rate [10]. In addition, complex parts with specific internal geometries and tight dimensional accuracy are usually required in aerospace and nuclear industries; hence, conventional machining would be 


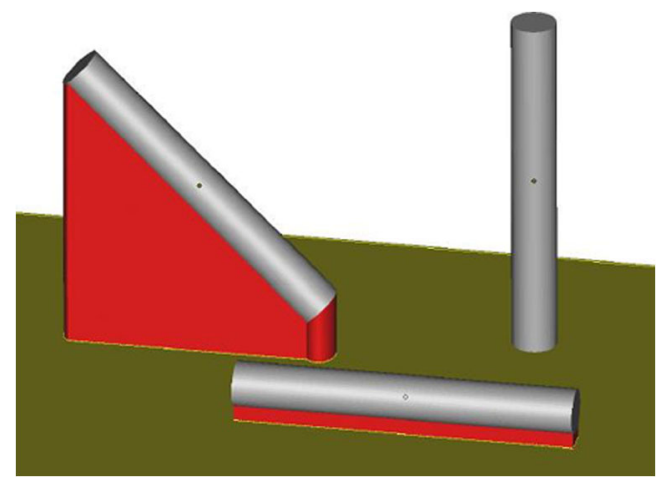

Fig. 1 Positioning of flat-, $45^{\circ}$-, and upright-built cylinder samples on the building plate

Table 1 Main features and processing parameters in LPBF of IN718 powder by means of $\mathrm{Yb}$ :YAG fiber laser

\begin{tabular}{ll}
\hline Parameter & Value \\
\hline Operating laser power & $195 \mathrm{~W}$ \\
Linear processing speed & $1.2 \mathrm{~m} \mathrm{~s}^{-1}$ \\
Hatch spacing & $90 \mu \mathrm{m}$ \\
Layer thickness & $20 \mu \mathrm{m}$ \\
Rotation between consecutive layers & $67^{\circ}$ \\
Focused spot diameter & $90 \mu \mathrm{m}$ \\
\hline
\end{tabular}

unfeasible [11]. Since IN718 is well known for good weldability, thanks to slow precipitation strengthening kinetics resulting in reduced cracking occurrence, LPBF is enabled [12].

As for any other metal alloy, the resulting mechanical properties upon AM are expected to depend on the final density. A function of heat and mass transfer may be found $[2,13]$, based on the main processing parameters such as the size of the laser beam, the laser power, the scanning speed, the layer thickness, and the hatch spacing $[14,15]$. Therefore, extensive research has been conducted to draw a correlation between densification and microstructure of IN178 and IN625 AMmade parts. Indeed, efforts have been made in predictive modeling [16-18] in order to investigate the correlation among temperature profile and material properties. It has been shown that optimum processing strategies result in $0.3 \%$ residual porosity, with elongated grains along the building direction [11]. Wear and high-temperature oxidation tests have been also implemented [19, 20], since poor resistance would lead to severe degradation of service life in the operating environment.

Anisotropy in the mechanical behavior is expected upon layering, depending on the direction of building, due to columnar grain growth as a consequence of directional thermal conduction. As regarding LPBF, anisotropy has been discussed in the literature for stainless steel [21, 22], titanium [23], and Ni-based alloys [24, 25]; anisotropy has also been reported when AM is conducted by means of electron beam [26]. This issue is expected to be crucial for Ni-based superalloys which are highly anisotropic and are conveniently processed to the purpose of producing functionally graded components [27], indeed. Interestingly, higher strength compared to the casted counterpart has been reported for IN738LC parts, whilst less significant differences have been shown at elevated temperature [25]. An approach to measure the degree of AMinduced anisotropy as a function of the direction of building has been proposed in the literature [22]: the normalized yield or ultimate tensile strengths have been evaluated with respect to their counterpart as resulting from an in-plane (i.e., flatbuilt) specimen. Depending on the base metal [21, 22, 24], normalized strength in LPBF has been found to range from 0.8 to 1.1. The position of building in the working area has even been suggested as possible additional reason of anisotropy [22], although this effect is thought to be negligible when focusing and deflecting are driven by means of an F-theta lenses providing uniform irradiance and approaching speed over the working surface [28].

It is worth noting that depending on the manufacturer and the powder size, arithmetic as-built roughness in LPBF
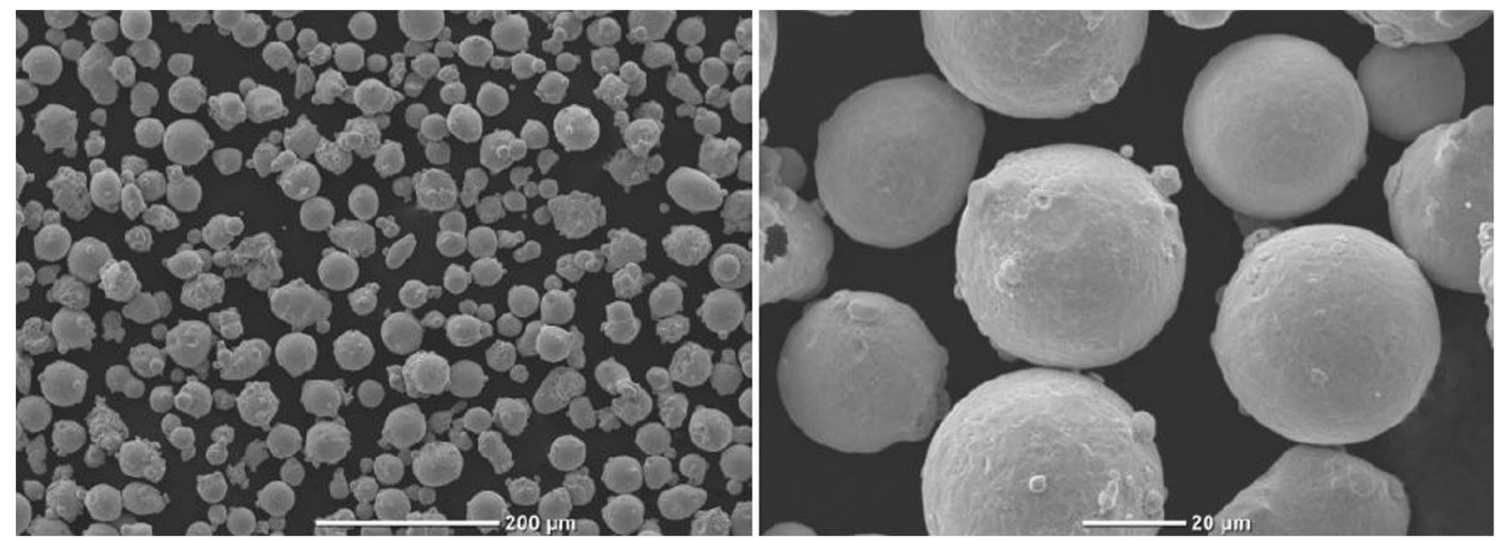

Fig. 2 Pre-alloyed, argon gas-atomized, virgin IN718 powder; electron microscopy 

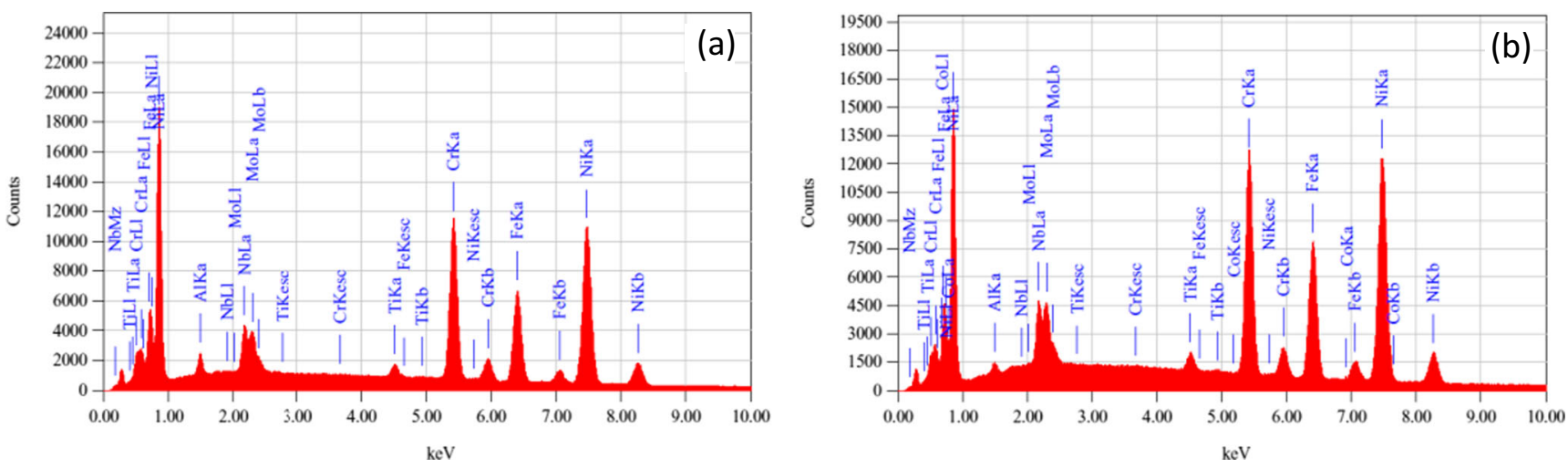

Fig. 3 Examples of acquired EDS spectra for a powder and $\mathbf{b}$ samples

Table 2 EDS inspections, average chemical composition (wt.\%) of powder and samples

\begin{tabular}{llllllll}
\hline & $\mathrm{Ni}$ & $\mathrm{Cr}$ & $\mathrm{Fe}$ & $\mathrm{Nb}$ & $\mathrm{Mo}$ & $\mathrm{Al}$ & $\mathrm{Ti}$ \\
\hline Powder & 52.28 & 19.74 & 17.30 & 5.35 & 2.88 & 1.40 & 1.03 \\
Std. dev. & 0.12 & 0.05 & 0.06 & 0.04 & 0.04 & 0.02 & 0.01 \\
Samples & 52.29 & 19.19 & 18.29 & 5.30 & 3.35 & 0.48 & 1.08 \\
Std. dev. & 0.12 & 0.05 & 0.05 & 0.04 & 0.04 & 0.01 & 0.01 \\
ASTM B637 & $50-55$ & $17-21$ & Bal. & $4.8-5.5$ & $2.8-3.3$ & $0.2-0.8$ & $0.7-1.2$ \\
\hline
\end{tabular}

usually ranges from 8 to $20 \mu \mathrm{m}$ [29]: since rough and rippled surfaces are reported to have larger stress concentrations, the rate of crack growth when testing as-built samples is affected [26]. In addition, residual stresses resulting from thermal cycles may exceed the yield strength, thus involving delamination during processing. Corrosion resistance, fracture toughness, crack growth behavior, and fatigue performance of the part could be even affected. With respect to this issue, IN718 parts have been found to be very susceptible to warping and buckling because of their higher residual stress to yield strength ratio [30]. Given this, neutron diffraction has been presented as a valid method to validate thermomechanical models so to predict the residual stresses on Ni-based AMmade parts [31]. Heat treatment is usually suggested to the concurrent purposes of stress relieving and precipitation of parent strengthening phase; size, shape, and fraction of precipitates in the matrix are affected [12].

To provide further understanding of the mechanical properties of IN718 AM-made parts, possible anisotropy is investigated in this paper as a function of the direction of growth. Flat-, $45^{\circ}$-, and upright-built samples have been produced. The tensile response at room and elevated temperature is discussed. Eventually, a batch of turbine blades, which are currently made via casting, has been manufactured and inspected by means of X-rays and 3D laser scanning metrology. Three possible directions of growing have been considered; corresponding supporting structures have been designed, accordingly. Although AM is not deemed to be a current viable option to casting, the process is intended to offer a valuable technical test model in the frame of advanced industrial prototyping to evaluate any possible upgrade at a predesign stage before flow production; furthermore, a preliminary evaluation of clamping and tooling for assembly is aimed. Therefore, proper mechanical features must be achieved and the same base metal must be used.

\subsection{Experimental procedure}

Pre-alloyed, $20 \mu \mathrm{m}$ mean grain size, virgin EOS IN718 powder resulting from argon gas atomization has been considered. An EOSINT M270 commercial laser sintering

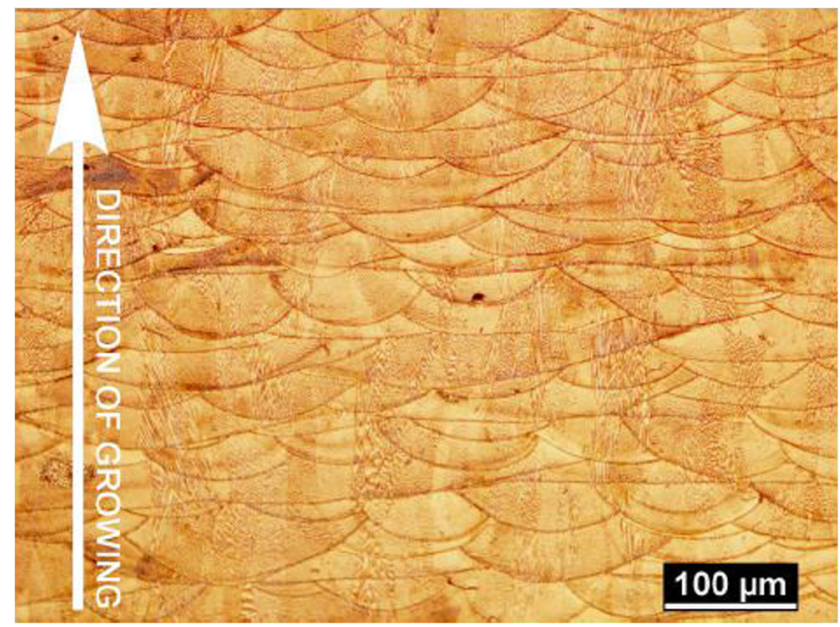

Fig. 4 Layer development; longitudinal cross section in the upright-built sample 


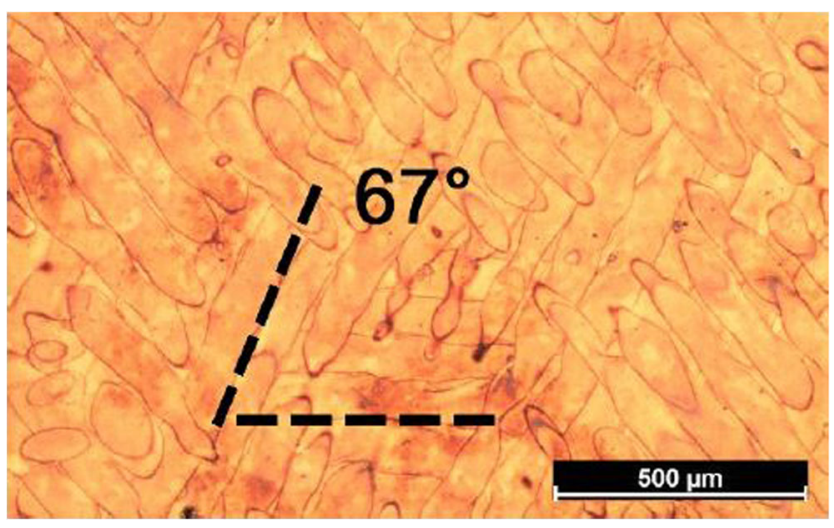

Fig. 5 Exposures over consecutive layers; transverse cross section in the upright-built sample

system with ytterbium-doped (Yb:YAG) fiber laser source has been used to manufacture a convenient number of cylinders (12 $\mathrm{mm}$ diameter, $90 \mathrm{~mm}$ height); an F-theta lens is used to focus and deflect the laser beam over the working area. Flat-, $45^{\circ}$-, and upright-built samples have been produced (Fig. 1) in 99.4\% pure argon inert atmosphere; supporting structures have been required on downward facing surfaces, depending on the sloping angle with the building direction, hence for flat- and $45^{\circ}$-built samples.

Operating laser power, speed, and hatching strategies are based on preliminary trials and are aimed to optimize LPBF and full dense structure (Table 1). A number of quality jobs have been performed to assess and fine-tune the beam offset and the scaling factor to address possible dimensional shrinkage. Namely, a scanning pattern with $67^{\circ}$ rotation of the scanning direction between consecutive $20-\mu \mathrm{m}$-thick layers has been set to improve densification. To the concurrent purpose of stress relieving and ductility improvement [9], heat treatment as per AMS 5664 standard (i.e., solution annealing at $1065^{\circ} \mathrm{C}$ for $1 \mathrm{~h}$, aging at $760^{\circ} \mathrm{C}$ for $10 \mathrm{~h}$, cooling to $650^{\circ} \mathrm{C}$, and holding for $8 \mathrm{~h}$ in argon inert atmosphere) has been eventually conducted before removal of the parts from the building plate, as suggested by the powder manufacturer [32].

Table 3 IN718 yield strength $\left(\mathrm{YS}_{0.2}\right)$ and ultimate tensile strength (UTS) at room and elevated temperature

\begin{tabular}{llllll}
\hline Sample & $\begin{array}{l}T \\
{\left[{ }^{\circ}\right]}\end{array}$ & $\begin{array}{l}\mathrm{YS}_{0.2} \\
{[\mathrm{MPa}]}\end{array}$ & $\begin{array}{l}\mathrm{R}_{\mathrm{YS}} \\
{[\mathrm{MPa} / \mathrm{MPa}]}\end{array}$ & $\begin{array}{l}\mathrm{UTS} \\
{[\mathrm{MPa}]}\end{array}$ & $\begin{array}{l}\mathrm{R}_{\mathrm{UTS}} \\
{[\mathrm{MPa} / \mathrm{MPa}]}\end{array}$ \\
\hline EOS reference & 24 & 1239 & & 1384 & \\
Flat-built & 24 & 1295 & 1.00 & 1484 & 1.00 \\
$45^{\circ}$-built & 24 & 1368 & 1.06 & 1521 & 1.02 \\
Upright-built & 24 & 1240 & 0.96 & 1398 & 0.94 \\
Flat-built & 650 & 1033 & 1.00 & 1139 & 1.00 \\
45-built & 650 & 1124 & 1.09 & 1187 & 1.04 \\
Upright-built & 650 & 978 & 0.95 & 1114 & 0.98 \\
\hline
\end{tabular}

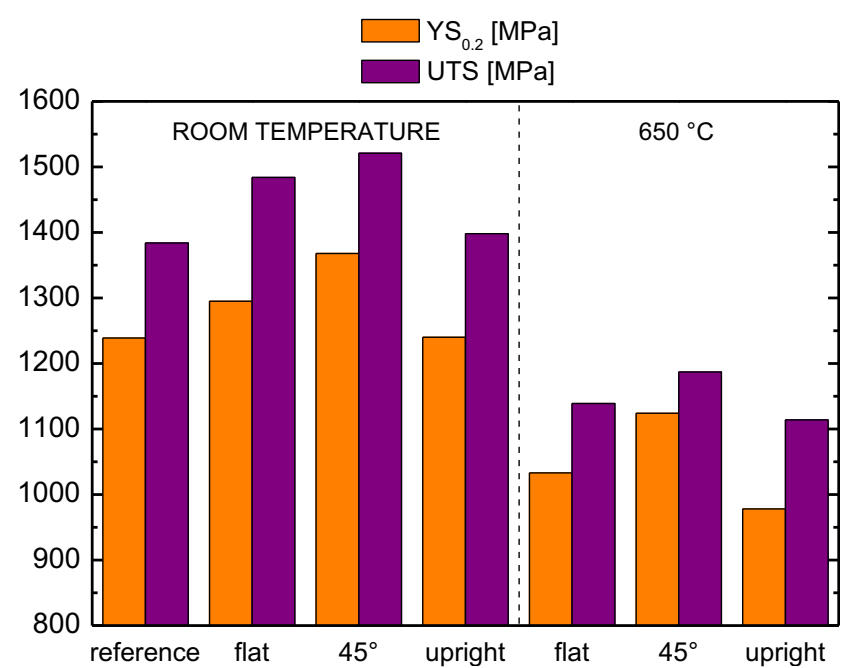

Fig. 6 IN718 yield strength $\left(\mathrm{YS}_{0.2}\right)$ and ultimate tensile strength (UTS) at room and elevated temperature

Subsize specimens with round cross section, as allowed by ASTM standards [33, 34], have been produced via turning of the cylinders to their contour, in agreement with similar research in the literature $[24,25]$. The same standards have been referred for testing at room and elevated temperature; namely, tensile testing at $650{ }^{\circ} \mathrm{C}$ has been conducted, being this the maximum operating temperature for IN718 AM-made parts under load, as per material data sheet [32]. Investigation on near-net-shape AM-made tensile specimens, with no effort to machine or grind the resulting surface, has been reported in the literature in case of flat specimens [22]. In this experimental campaign instead, an investigation on as-built parts is not feasible, given a mean arithmetic roughness ranging from 5 to
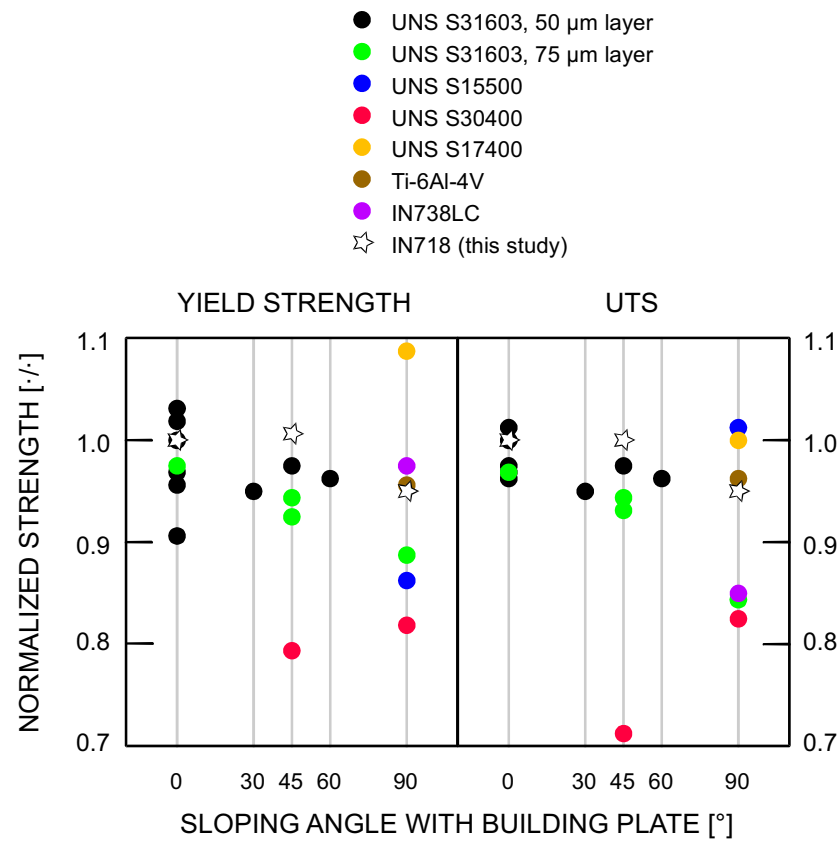

Fig. 7 Normalized strength resulting from LPBF; adaptation and upgrade based on the literature [22] 
Table 4 Average decrease of mechanical properties at $650{ }^{\circ} \mathrm{C}$ with temperature respect to room

\begin{tabular}{lll}
\hline Sample & $\begin{array}{l}\Delta \mathrm{YS}_{0.2} \\
{[\%]}\end{array}$ & $\begin{array}{l}\Delta \text { UTS } \\
{[\%]}\end{array}$ \\
\hline Flat-built & 20 & 23 \\
$45^{\circ}$-built & 18 & 22 \\
Upright-built & 21 & 20 \\
\hline
\end{tabular}

$20 \mu \mathrm{m}$ over as-built surfaces, depending on the sloping angle with the building direction. Therefore, in order to provide uniform, improved surface quality to the purpose of reliable tensile testing, post-processing would be required anyway. Eventually, average roughness has been reduced below $0.5 \mu \mathrm{m}$ upon turning.

EDS inspections have been conducted both on virgin powder and random cross sections of the samples, to assess possible variation in the nominal composition upon LPBF; $15 \mathrm{kV}$ accelerating voltage, $1 \mathrm{nA}$ probe current, and 3 min probing live time have been set.

The same processing parameters and scanning strategies have been used to manufacture the turbine blades, whose airfoil and dovetails are $50 \mathrm{~mm}$ long, $20 \mathrm{~mm}$ wide, approximately. As for the tensile specimens, heat treatment as per AMS 5664 standard has been conducted. X-ray inspections have been performed to assess the occurrence of possible lack of fusion, inclusions, and cracks. Laser scanning has been eventually conducted to evaluate any possible deviation from the intended geometry.

\section{Results and discussion}

\subsection{Composition and construction}

The powder has been preliminarily inspected in terms of size and geometry, since specific requirements of shape must be matched to the purpose of proper manufacturing. Spherical and near-spherical grains have been found (Fig. 2); thus, efficient flowing and layer packaging are expected to result in uniform melting [35].

Furthermore, the virgin powder and a number of samples in the suggested processing conditions have been investigated via areal and punctual EDS inspections. The acquired spectra and the chemical compositions have been compared (Fig. 3, Table 2). An average overall fitting coefficient of the quantitative analysis (i.e., the residual between the acquired and the synthetic spectra) of 1.9 and $2.9 \%$ resulted for the powder and the samples, respectively. It is worth noting that the ASTM B637 standard has been matched in terms of nominal chemical composition, although certain elements below $1 \%$ wt. have not been detected. Random transverse and longitudinal cross sections of the samples have also been considered; based on these, one may infer the referred nominal chemical composition has been taken during processing. Interestingly, high chemical homogeneity has been found, in agreement with similar studies in the literature [25].

Uniform fusion has been experienced. To further discuss this, a number of cross sections have been examined. Overlapping lenticular-shaped melting pools resulted as a consequence of building and layer development (Fig. 4); it is worth noting that although a scanning beam of theoretical $90 \mu \mathrm{m}$ diameter is used, a wider scanning trace of approximately $120 \mu \mathrm{m}$ width has been found due to thermal conduction. Moreover, the typical $67^{\circ}$ scanning angle between exposures over consecutive layers has been measured if a cross section is made orthogonal to the direction of growing (Fig. 5).

\subsection{Tensile testing}

The outcome of tensile testing has been discussed as a function of temperature $T$ and sloping angle with the building direction (Table 3, Fig. 6) in comparison with the expected mechanical properties as per material data sheet [32], where available. Three specimens for each building direction have been tested; average values of yield strength for a $0.2 \%$ offset $\left(\mathrm{YS}_{0.2}\right)$ and ultimate tensile strength (UTS) are given. The degree of AM-induced anisotropy has been measured in terms of normalized strength $R$ with respect to a flat-built specimen, as suggested in the literature [22].

Ductile fracture has been experienced, irrespective of the sample and the temperature. As regarding testing at room temperature, both the referred average $\mathrm{YS}_{0.2}$ and UTS are available with $100 \mathrm{MPa}$ uncertainty [32] to take account of possible
Fig. 8 Flat-, $45^{\circ}$-, and uprightbuilt turbine blades: positioning in building
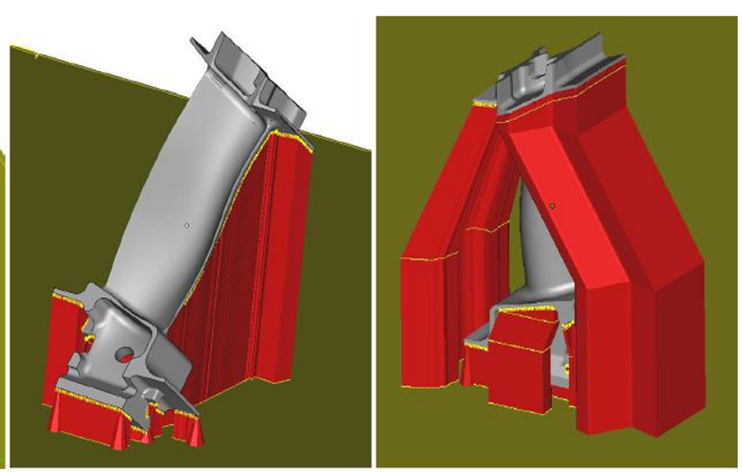
Fig. 9 Flat-, $45^{\circ}$-, and uprightbuilt turbine blades: detail of cone-shaped supports on the dovetail; line and block supporting along the dovetail are dismissed in the pictures
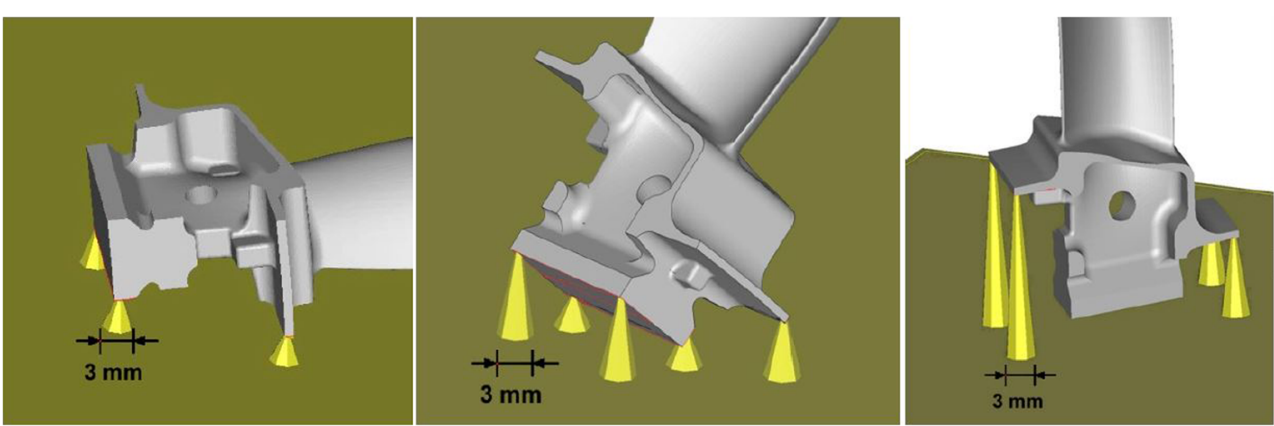

anisotropy; hence, the results have been found to fall within the expected range. Also, based on the normalized strengths, the degree of AM-induced anisotropy is negligible from a technological point of view, its value being in agreement with similar, available findings in the literature (Fig. 7). Therefore, the optimization of the processing parameters and the scanning patterns is effective; one may infer uniform mechanical properties are achieved on a complex real component experiencing different loading conditions (i.e., loading directions) when in service.

Nevertheless, it is worth noting that higher $\mathrm{YS}_{0.2}$ and UTS have been found for the $45^{\circ}$-built specimen. A favorable stress state can be referred as possible reason: as a general rule, fracture is induced over planes where maximum shear stress occurs; these are $45^{\circ}$ from the direction of loading, hence are parallel to layering when testing $45^{\circ}$-built specimens. Since bonding among layers may be incomplete, failure is thought to be deferred when layers are pulled together in parallel.

As regarding testing at elevated temperature, reference properties are not available by the manufacturer, although possible comparisons could be drawn based on wrought parent metal. Nevertheless, to the purpose of this paper, it is worth noting that any decrease $\Delta$ of $\mathrm{YS}_{0.2}$ and UTS is deemed to be independent on the building direction (Table 4). Moreover, as for testing at room temperature, although the degree of anisotropy has been found to be low, higher $\mathrm{YS}_{0.2}$ and UTS are found for the $45^{\circ}$-built specimen; the same reason applies.

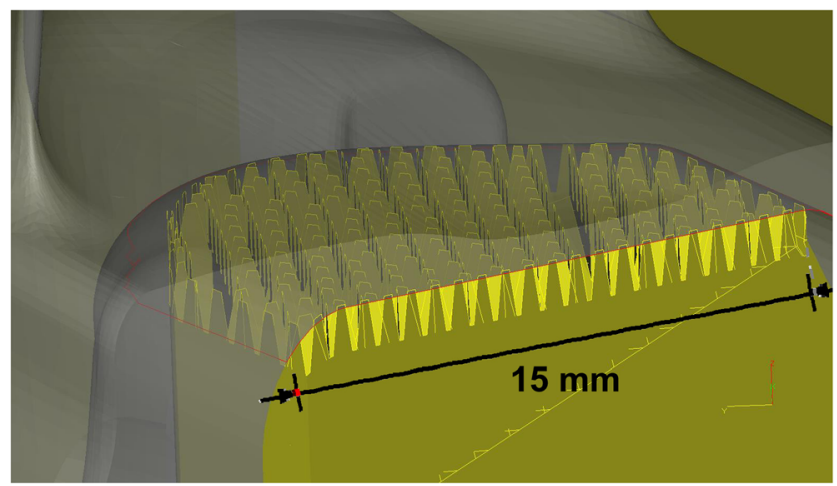

Fig. 10 Detail of teething at the interface between block supports and the dovetail in upright building

\subsection{Turbine blades}

Based on the outcome of tensile testing, anisotropy is negligible; hence, the overall mechanical properties are not affected by positioning. Therefore, any part with a shape suggesting a natural preferential direction of growing could be equally manufactured to the purpose of accommodating proper supports and concurrently reducing the overall building time; the same mechanical strength must be expected.

Among all possible directions of growing, three of these have been investigated, the longitudinal axis of the airfoil being taken to $0^{\circ}, 45^{\circ}$, and $90^{\circ}$ to the building plate (Fig. 8). Depending on positioning, proper supporting by means of auxiliary structures would be required. Namely, an ideal balance must be found between two needs: reducing the amount of supports to preserve functional surfaces and allow the removal of the part; preventing warping and collapse of crucial surfaces exceeding a given threshold depending on both the material and the machine [36]. Cone-shaped supports (Fig. 9) have been preferred at the edge of the dovetail to increase the extent of the interface with the building plate; line supporting has been provided along the dovetail instead. Teeth at the interface between block supports and parts (Fig. 10) have been conveniently adjusted in number and size (i.e., height, length, and spacing) depending on the supported part. The airfoil is self-supported in the upright-built sample; hence, additional supporting is prevented on a crucial surface.

Reduced building time has been benefited for flat- and $45^{\circ}$-built samples in comparison with the upright-built sample, thanks to shorter building height (Table 5). On the other hand, reduced and easier post-processing has been required for the latter, since the surface quality of

Table 5 Building time of the turbine blades as a function of positioning; manufacturing of one part per job

\begin{tabular}{lll}
\hline Positioning & Manufacturing time & Building height \\
\hline Flat-built & $8 \mathrm{~h}, 26 \mathrm{~min}$ & $33 \mathrm{~mm}$ \\
$45^{\circ}$-built & $17 \mathrm{~h}, 13 \mathrm{~min}$ & $75 \mathrm{~mm}$ \\
Upright-built & $22 \mathrm{~h}, 10 \mathrm{~min}$ & $90 \mathrm{~mm}$ \\
\hline
\end{tabular}


Fig. 11 Flat-, $45^{\circ}$-, and uprightbuilt turbine blades: as-built, with supporting structures on the building plate
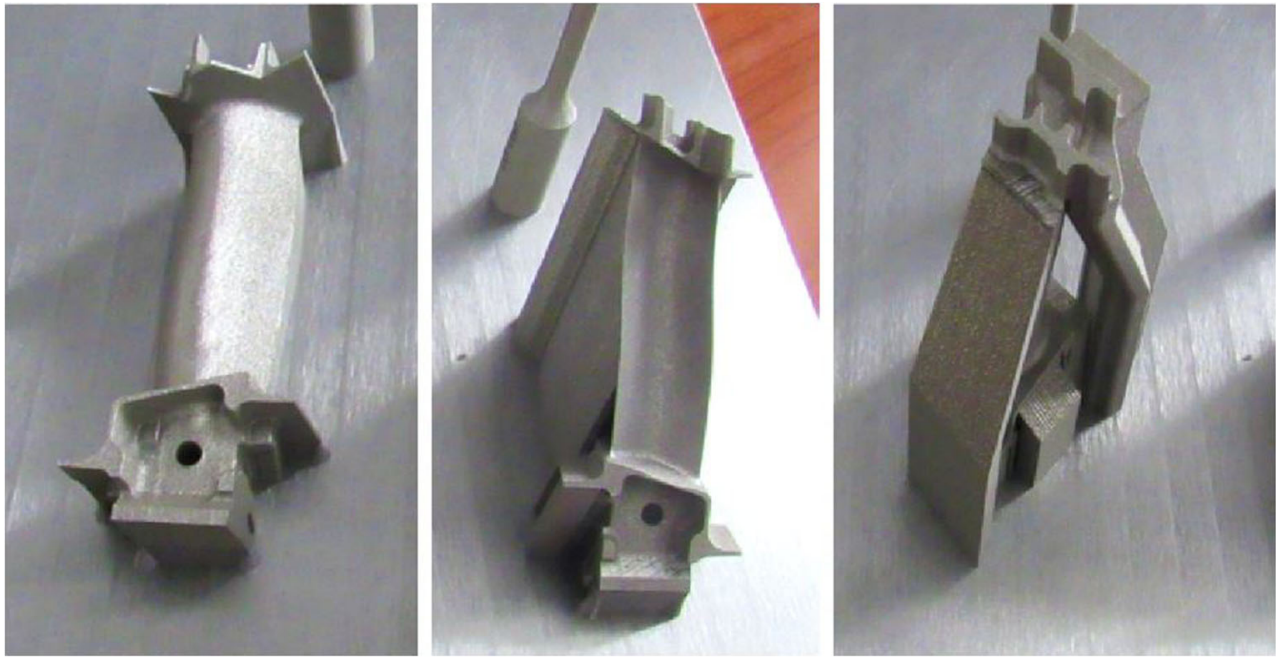

the airfoil has not been affected by supporting. Manufacturing of the turbine blades has been possible for any given positioning (Fig. 11, Fig. 12); sound and defect-free parts resulted no indications have been shown via X-ray inspections (Fig. 13).

Further conclusions can be drawn based on the outcome of laser metrology (Fig. 14). Irrespective of positioning, the dovetails are found to comply with the intended geometry. As expected, removal of the supports from the flat-built sample has been challenging and time-consuming; this direction of growing is not suggested, accordingly. As regarding the upright-built sample, it is worth noting that although the airfoil being self-supporting, warping resulted with a maximum mismatch in the order of $0.3 \mathrm{~mm}$ at the trailing edge. Convincing results have been achieved with the $45^{\circ}$-built sample instead: a mismatch in the order of $0.2 \mathrm{~mm}$ has been measured at the convex side of the airfoil, but since the nominal curvature has been matched, the issue is deemed to result from improper dressing in post-processing. The effectiveness of the part in a preliminary evaluation of tooling and clamping is not affected; nevertheless, proper machining allowance could be set to
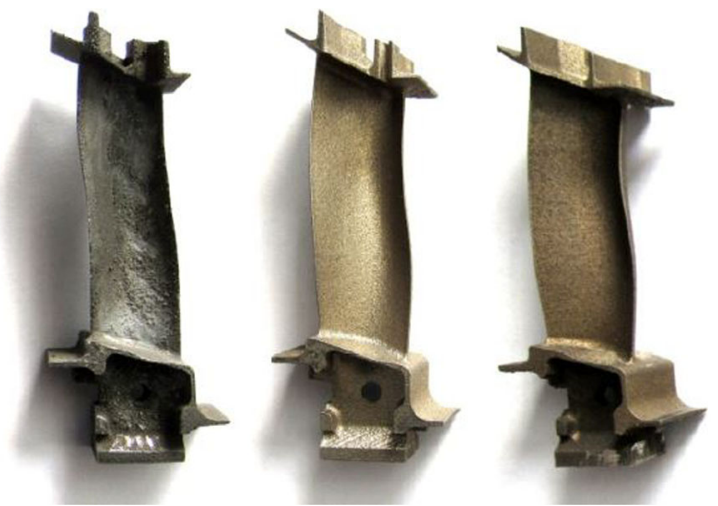

$10 \mathrm{~mm}$

Fig. 12 Flat-, $45^{\circ}$-, and upright-built turbine blades removed from the building plate and heat treated prevent any minimal mismatch. Therefore, when balancing the overall processing time and the general features, manufacturing of the $45^{\circ}$-built sample should be preferred, being this an ideal compromise among multiple needs.

\section{Conclusions}

A number of main findings have been drawn in the frame of additive manufacturing of superalloy Inconel 718 by means of laser powder-bed fusion. At first, uniform fusion has been experienced and convincing matching with the intended geometry has been achieved upon proper settings of the processing parameters, based on preliminary optimization and fine-tuning.

As regarding the mechanical properties, anisotropy is considered to be negligible from a technological point of view when measured in terms of normalized strength, both at room and elevated temperature. These findings are deemed to be

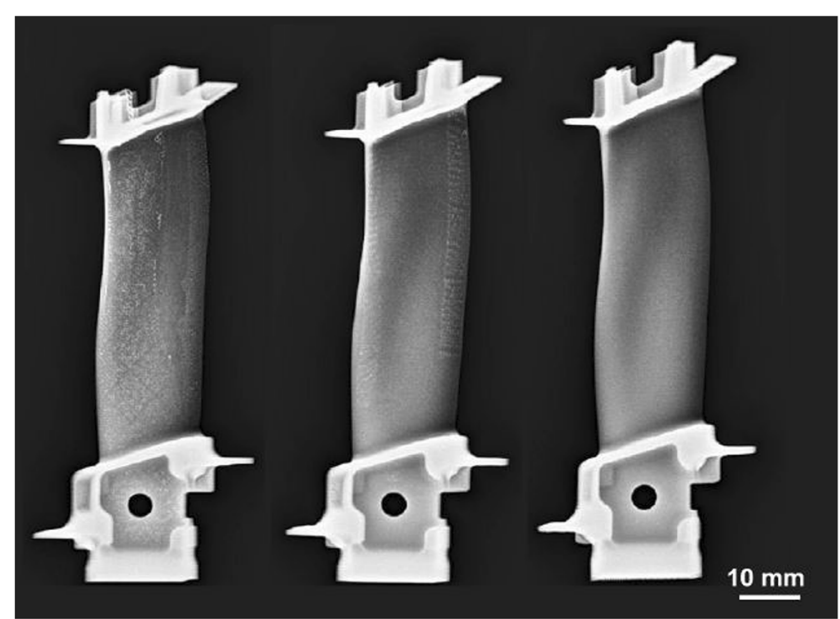

Fig. 13 Flat-, $45^{\circ}$-, and upright-built turbine blades: X-ray transmitted images 

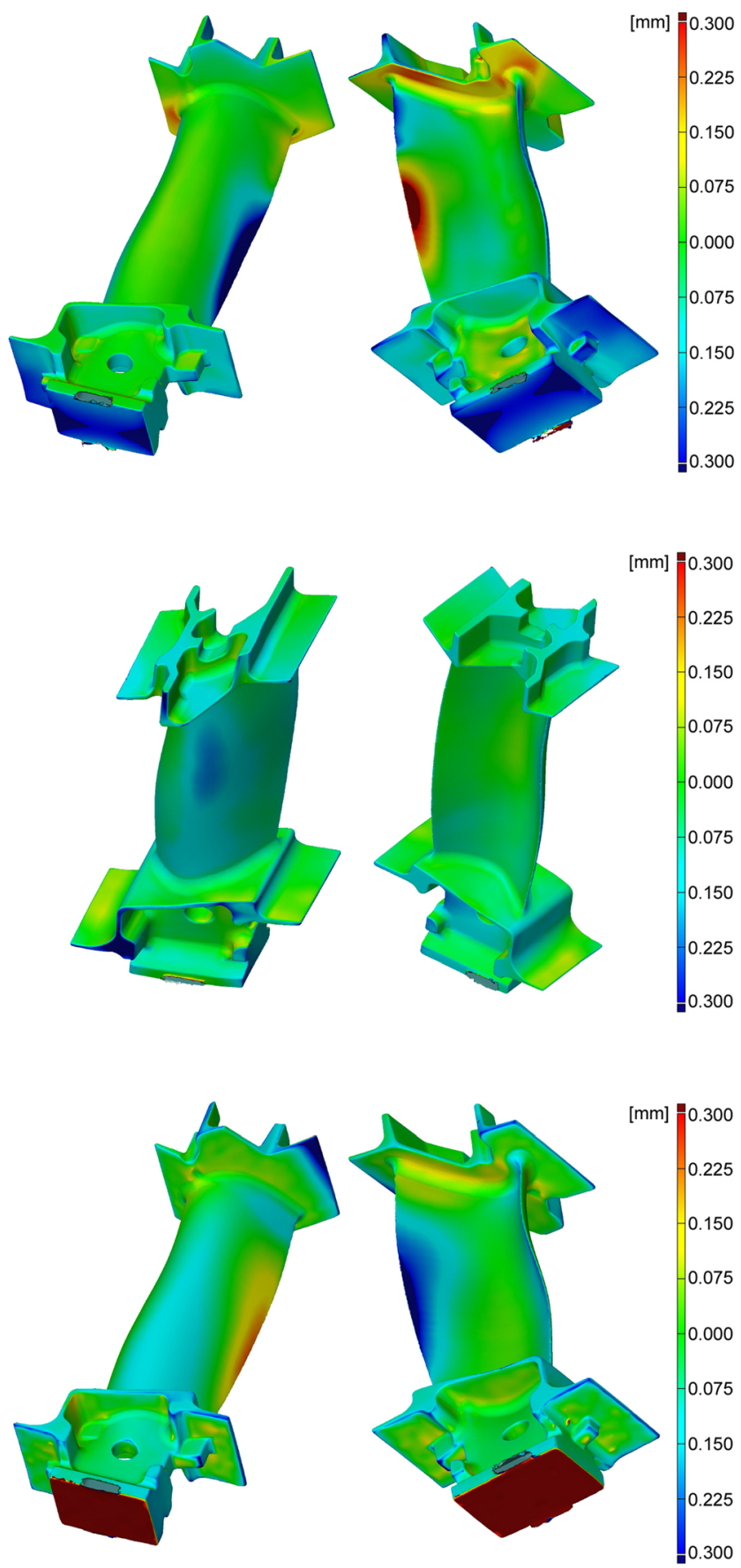

Fig. 14 Flat-, $45^{\circ}$-, and upright-built turbine blades: evaluation of mismatch by means of laser metrology in comparison with the intended nominal geometry

valuable for a number of reasons: at first, to the purpose of setting a shared joint knowledge about anisotropy of common metals in additive manufacturing; moreover, new information concerning the mechanical response have been made available at high temperature. Namely, any decrease of yield and ultimate tensile strength at the maximum allowed operating temperature of the parts has been found to be independent on the building direction. This is thought to be relevant in the current research and industrial frame of developing a general knowledge regarding additive manufacturing: indeed, since the mechanical properties are not affected by positioning, job planning could be driven by the mere purpose of accommodating proper supports and concurrently reducing the overall building time.

It is worth noting that although the mechanical properties are expected to be the same, multiple issues should be taken into account in practice, including the need for postprocessing to remove the supporting structures and reduce the surface roughness. Moreover, based on laser metrology on the test article, it has been found that proper machining allowance may be required to prevent any minimal mismatch, in the order of $0.2 \mathrm{~mm}$, from the intended geometry.

Beyond these, the paper has been even aimed to offer few general guidelines for positioning and support designing in job planning for laser powder-bed fusion, when approaching a complex part such as a turbine blade.

Open Access This article is distributed under the terms of the Creative Commons Attribution 4.0 International License (http:// creativecommons.org/licenses/by/4.0/), which permits unrestricted use, distribution, and reproduction in any medium, provided you give appropriate credit to the original author(s) and the source, provide a link to the Creative Commons license, and indicate if changes were made.

\section{References}

1. Emmelmann C, Sander P, Kranz J, Wycisk E (2011) Laser additive manufacturing and bionics: redefining lightweight design. Phys Procedia 12:364-368

2. Khairallah S, Anderson A, Rubenchik A, King W (2016) Laser powder-bed fusion additive manufacturing: physics of complex melt flow and formation mechanisms of pores, spatter, and denudation zones. Acta Mater 108:36-45

3. Tolochko N, Mozzharov S, Laoui T, Froyen L (2003) Selective laser sintering of single- and two-component metal powders. Rapid Prototyp J 9(2):68-78. doi:10.1108/13552540310467077

4. Kruth JP, Froyen L, Van Vaerenbergh J, Mercelis P, Rombouts M, Lauwers B (2004) Selective laser melting of iron-based powder. J Mater Process Tech 149:616-622

5. Yadollahi A, Shamsaei N (2017) Additive manufacturing of fatigue resistant materials: challenges and opportunities. Int J Fatigue 98: $14-31$

6. Alfieri V, Argenio P, Caiazzo F, Sergi V (2016) Reduction of surface roughness by means of laser processing over additive manufacturing metal parts. Materials 10(1):30. doi:10.3390/ ma10010030

7. Baicheng Z, Xiaohua L, Jiaming B, Junfeng G, Pan W, Chen-nan S, Muiling N, Guojun Q, Jun W (2017) Study of selective laser melting (SLM) Inconel 718 part surface improvement by electrochemical polishing. Mater Design 116:531-537

8. Uriondo A, Esperon-Miguez M, Perinpanayagam S (2015) The present and future of additive manufacturing in the aerospace sector: a review of important aspects. J Aerospace Eng 229(11):21322147

9. Reed R (2006) The superalloys, fundamentals and applications. Cambridge University Press, New York 
10. Youssef HA (2016) Machining of stainless steels and super alloys: traditional and nontraditional techniques. John Wiley \& Sons, New York

11. Choi JP, Shin GH, Sangsun Y, Yang DY, Lee JS, Brochu M, Yu JH (2017) Densification and microstructural investigation of Inconel 718 parts fabricated by selective laser melting. Powder Technol 310:60-66

12. Tucho WM, Cuvillier P, Sjolyst-Kverneland A, Hansen V (2017) Microstructure and hardness studies of Inconel 718 manufactured by selective laser melting before and after solution heat treatment. Mat Sci Eng A-Struct 689:220-232

13. Xia M, Gu D, Yu G, Dai D, Chen H, Shi Q (2016) Influence of hatch spacing on heat and mass transfer, thermodynamics and laser processability during additive manufacturing of Inconel 718 alloy. Int J Mach Tool Manu 109:147-157

14. Steen W, Mazumder J (2010) Laser material processing. Springer, London

15. Cardaropoli F, Alfieri V, Caiazzo F, Sergi V (2012) Dimensional analysis for the definition of the influence of process parameters in selective laser melting of Ti-6Al-4V alloy. J Eng Manuf 226(7): 1136-1142. doi:10.1177/0954405412441885

16. Criales LE, Arısoy YM, Özel T (2016) Sensitivity analysis of material and process parameters in finite element modeling of selective laser melting of Inconel 625. Int J Adv Manuf Technol 86(9-12): 2653-2666

17. Criales LE, Arısoy YM, Lane B, Moylan S, Donmez A, Özel T (2017) Predictive modeling and optimization of multi-track processing for laser powder bed fusion of nickel alloy 625. Addit Manuf 13:14-36

18. Criales LE, Arisoy YM, Lane B, Moylan S, Donmez A, Özel T (2017) Laser powder bed fusion of nickel alloy 625: experimental investigations of effects of process parameters on melt pool size and shape with spatter analysis. Int J Mach Tools Manuf, https://doi.org/ 10.1016/j.ijmachtools.2017.03.004

19. Jia Q, Dongdong G (2014) Selective laser melting additive manufactured Inconel 718 superalloy parts: high-temperature oxidation property and its mechanisms. Opt Laser Technol 62:161171

20. Jia Q, Dongdong G (2014) Selective laser melting additive manufacturing of Inconel 718 superalloy parts: densification, microstructure and properties. J Alloy Compd 585:713-721

21. Tolosa I, Garciandía F, Zubiri F, Zapirain F, Esnaola A (2010) Study of mechanical properties of AISI 316 stainless steel processed by "selective laser melting", following different manufacturing strategies. Int J Adv Manuf Tech 51(5-8):639-647

22. Luecke WE, Slotwinski JA (2014) Mechanical properties of austenitic stainless steel made by additive manufacturing. J Res Natl Inst Stan 119:398-418

23. Rafi HK, Starr TL, Stucker BE (2013) A comparison of the tensile, fatigue, and fracture behaviour of Ti6Al4V and 15-5 PH stainless steel parts made by selective laser melting. Int J Adv Manuf Tech 69(5-8):1299-1309

24. Rickenbacher L, Etter T, Hovel S (2013) High temperature material properties of IN738LC processed by selective laser melting (SLM) technology. Rapid Prototyp J 19(4):2082-2090

25. Kunze K, Etter T, Grasslin J, Shklover V (2014) Texture, anisotropy in microstructure and mechanical properties on IN738LC alloy processed by selective laser melting (SLM). Mat Sci Eng A-Struct 620:213-222

26. Ladani L, Roy L (2013) Mechanical behavior of the Ti-6Al-4V manufactured by electron beam additive fabrication. Proceeding of the ASME 2013 International Manufacturing Science and Engineering Conference MSEC2013, Madison, WI, USA doi:10. 1115/MSEC2013-1105

27. Popovich VA, Borisov EV, Popovich AA, Sufiiarov VS, Masaylo DV, Alzina L (2017) Functionally graded Inconel 718 processed by additive manufacturing: crystallographic texture, anisotropy of microstructure and mechanical properties. Mater Design 114:441-449

28. Muth M (1996) Optimized x/y scanning head for laser beam positioning. Proceedings of SPIE 2774, Design and Engineering of Optical Systems 535, Glasgow, UK. doi:10.1117/12.246700

29. Alrbaey K, Wimpenny D, Tosi R, Manning W, Moroz A (2014) On optimization of surface roughness of selective laser melted stainless steel parts: a statistical study. J Mater Eng Perform 23(6):2139 2148. doi:10.1007/s11665-014-0993-9

30. Mukherjee T, Zhang W, DebRoy T (2017) An improved prediction of residual stresses and distortion in additive manufacturing. Comput Mater Sci 126:360-372

31. Wang Z, Denlinger E, Michaleris P, Stoica AD, Ma D, Beese AM (2017) Residual stress mapping in Inconel 625 fabricated through additive manufacturing: method for neutron diffraction measurements to validate thermomechanical model predictions. Mater Design 113:169-177

32. EOS (2014) EOS NickelAlloy IN718. EOS GmbH - Electro Optical Systems, München

33. ASTM (2016) ASTM E8 / E8M-16a - Standard test methods for tension testing of metallic materials. ASTM International, West Conshohocken

34. ASTM (2009) ASTM E21-09 Standard test methods for elevated temperature tension tests of metallic materials. ASTM International, West Conshohocken

35. Murr LE, Gaytan SM, Ramirez DA, Martinez E, Hernandez J, Amato KN, Shindo PW, Medina FR, Wicker RB (2012) Metal fabrication by additive manufacturing using laser and electron beam melting technologies. J Mater Sci Technol 28(1):1-14

36. Calignano F (2014) Design optimization of supports for overhanging structures in aluminum and titanium alloys by selective laser melting. Mater Design 64:203-213 